\title{
AVALIAÇÃO DA IMPLEMENTAÇÃO DA PNSIPN: UMA ANÁLISE DA FORMAÇÃO PROFISSIONAL E DA PRODUÇÃO CIENTÍFICA SOBRE SAÚDE DA POPULAÇÃO NEGRA
}

\author{
$\underline{\text { Adivânia Tolentino Nogueira }}{ }^{1}$; Edna Maria de Araujo²
}

1. Bolsista PROBIC/UEFS, Graduanda de Medicina, Universidade Estadual de Feira de Santana, e-mail: adivania.nogueira@gmail.com

2. Orientadora, Departamento de Saúde, Universidade Estadual de Feira de Santana, e-mail: ednakam@gmail.com

PALAVRAS-CHAVE: Política de Saúde; etnia e saúde; avaliação

\section{INTRODUÇÃO}

A Política Nacional de Saúde Integral da População Negra foi aprovada no ano de 2009 pelo Conselho Nacional de Saúde, como um instrumento que tem por objetivo combater a discriminação étnico-racial no Sistema Único de Saúde, bem como promover a eqüidade em saúde da população negra (Ministério da Saúde, 2010). Essa política define os princípios, a marca, os objetivos, as diretrizes, as estratégias e as responsabilidades de gestão, voltados para a melhoria das condições de saúde da população negra.

A PNSIPN, da mesma forma que o processo para a sua formulação, continua valorizando a pesquisa científica como condutora das ações de implantação da política. Em seu artigo VI estabelece a necessidade do desenvolvimento de processos de informação, comunicação e educação que desconstruam estigmas e preconceitos. Para isso, incentiva à produção do conhecimento cientifico que, de um lado, decorre dos fenômenos que se manifestam nas práticas cotidianas, de outro, requer que os espaços formativos sejam também de produção de conhecimento que não se restringem, apenas, às universidades e institutos de pesquisa (MONTEIRO, 2010).

De acordo com o Portal da Saúde [...] investimento em pesquisas em saúde contribui para o preenchimento de lacunas de conhecimento em áreas prioritárias para a população, interligando o mundo acadêmico e as necessidades de saúde das pessoas (BRASIL, 2013).

Esta pesquisa se desenvolveu no campo da investigação científica com o objetivo de identificar, descrever e analisar as produções sobre a Saúde da População Negra em artigos, teses e dissertações digitais brasileiras e compreender como as Universidades Públicas vem se organizando, desenvolvendo suas atividades em torno do tema da Saúde da População Negra e se posicionando com relação ao processo de formulação e implementação da Política de Saúde da População Negra nos últimos 8 anos.

\section{MATERIAL E MÉTODOS OU METODOLOGIA (ou equivalente)}

Para este estudo foi utilizada a concepção de pesquisa avaliativa, que consiste em fazer um julgamento posterior a uma intervenção ou a uma ação social usando métodos científícos.

A dimensão utilizada no estudo foi a avaliação com abordagem quantitativa da implementação da política por meio da análise do indicador de ensino e pesquisa, contendo parâmetros, fontes, meios de verificação e premissas esperadas. As técnicas de coleta utilizadas foram a análise dos Projetos pedagógicos (PPP) dos cursos de graduação de saúde (enfermagem, medicina, fisioterapia, nutrição, psicologia, serviço social, e odontologia) das universidade públicas da Bahia e São Paulo e a busca na literatura científica nas seguintes bases 
de dados on-line: Pubmed/Medline, Scielo, LILACS e BIREME., entre o período de 2010 e 2016, utilizando-se descritores relacionados a etnia, população negra, desigualdades em saúde e raça; Vulnerabilidade em Saúde; desigualdades em saúde; e Doença falciforme. Considerando a dificuldade de obter o PPP diretamente com as Universidades, optou-se por realizar a busca nas páginas oficiais dos cursos e/ou universidades. A fim de sistematizar e fazer uma análise homogênea, construiu-se matriz de análise, contento informações sobre os cursos da área de saúde existentes na Universidade, o ano de atualização do PPP e as informações da inclusão da temática de saúde da população negra na grade curricular.

Para os resultados utilizou-se de tabelas e relatos colhidos dos próprios PPP, para responder o questionamento: "As instituições públicas de ensino superior possuem disciplinas na grade curricular que contemplem a abordagem étnico racial nos cursos de saúde (enfermagem, medicina, fisioterapia, psicologia e odontologia)?". Como parâmetro buscou-se que $50 \%$ dos cursos da graduação tivessem abordagem étnico racial.

\section{RESULTADOS E/OU DISCUSSÃO (ou Análise e discussão dos resultados)}

\section{Resultados 1: A PNSIPN e Projetos Pedagógicos de cursos de graduação em saúde: quais as mudanças?}

Das Universidades analisadas: 6 universidades na Bahia e 8 universidades em São Paulo

1- Quanto a abordagem do tema e a importância obrigatória da disciplina: 40\% dos cursos das Universidades baianas incluíram temas sobre Racismo e Saúde da População Negra no processo de formação dos acadêmicos. Todas como subtema de um componente curricular mais amplo, não existindo disciplina própria para a temática. Sendo destas disciplinas, $67 \%$ disciplinas obrigatórias e 33\% disciplinas optativas. Nas Universidades paulistas $25 \%$ incluíram a ementa na formação dos acadêmicos. Dessa porcentagem, nenhum curso das Universidades tinha uma disciplina própria para temática.

2- Quanto aos temas explorados nos currículos: mais discutido é a influência da raça como determinantes das condições de saúde e de doença, destacar-se a ementa do curso de Medicina da Universidade Federal do Recôncavo Baiano e a disciplina optativa "Gênero, Raça e Saúde" que estimula nos discentes a capacidade de "produzir tecnologias de educação em saúde para eliminação das discriminações, estigmas, estereótipos e preconceitos racistas e sexistas (PPP- Medicina/UFRB, 2014).

Dessa forma: a minoria das instituições públicas de ensino superior possui disciplinas na grade curricular que contemplem a abordagem étnico racial nos cursos de saúde.

\section{Resultado 2: ESTADO DE ARTE DA PRODUÇÃO CIENTÍFICA SOBRE SAÚdE DA POPULAÇÃO NEGRA (2009-2016)}

Observou-se crescimento na abordagem da temática nos anos de 2009, 2013 e 2014 com pelo menos 15 publicações anuais. No entanto, nos anos subsequentes, as publicações diminuíram sensivelmente, com 11 publicações em 2015 e 3 em 2016, um fator negativo para implantação da política. Os estados com mais publicações foram: Bahia, São Paulo e Rio de Janeiro; nos outros, notou-se baixa produção, apenas $18(66,7 \%)$ das 27 unidades federativas brasileiras, apresentaram uma média de dois trabalhos sobre a Saúde da População Negra publicados. Quanto a temática destacou-se em 40\% (36 artigos) a população quilombola, sendo um avanço, considerando a invisibilidade do tema no âmbito científico.

A descrição e análise dos resultados encontrados a partir do processamento das informações extraídas dos resumos selecionados estão apresentadas a seguir.

Procedência institucional dos autores 
Foram identificadas as instituições nas quais os autores dos trabalhos estavam vinculados, e depois as Universidades foram agrupadas por estados. Gráfico 2: Procedência Institucional. Fonte: Fonte: Banco de Teses da CAPES, SciELO, BVS e PUBMED (2009-2016)

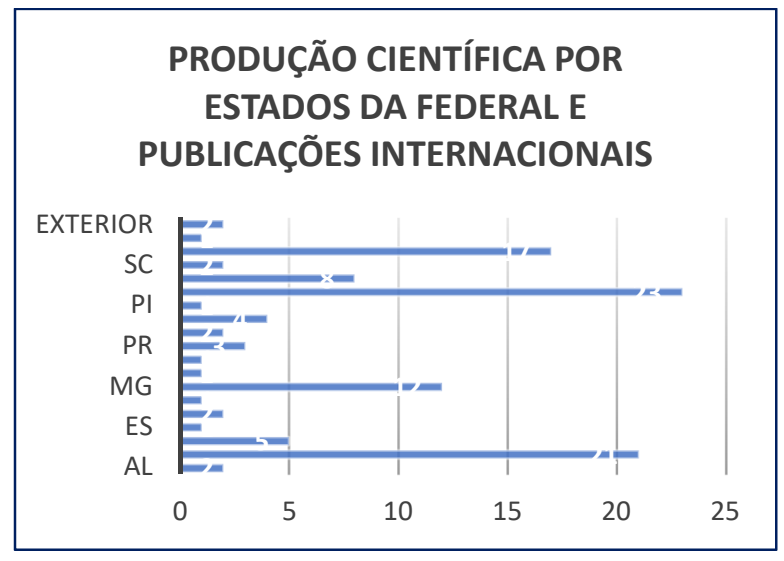

Os estados de São Paulo, Rio de Janeiro e Bahia apresentaram maior número de publicações científicas, inferindo-se que há nestes estados maior visibilidade a saúde da população negra e à temática fomentada pela PNSIPN. Nas demais unidades federativas, notou-se baixa produção, sendo que apenas $18(66,7 \%)$ das 27 unidades federativas brasileiras, apresentaram, no mínimo, dois trabalhos sobre a Saúde da População Negra, seja em formato de artigo, tese ou dissertação. É importante observar que houve estudos publicados em revistas internacionais.

\section{Classificação segundo temática}

$\mathrm{Na}$ abordagem temática, as produções científicas foram bem abrangentes nas discussões de questões sobre população quilombola, intersecção entre saber científica e os saberes das religiões de matriz africana, população negra e HIV, e a questão da raça/cor como importante dado epidemiológico explorando nesta área o problema da autodeclaração e da interpretação do pesquisador, e também da importância desse dados para o preenchimento dos formulário dos Sistemas de Informação em Saúde, em especial, o Sistema de Mortalidade em Saúde.

Em relação aos artigos destacou-se em 40\% (36 artigos) a discussão de temas voltados para a população quilombola. $O$ destaque a esta população específica é visto como uma contribuição importante para a implantação da PNSIPN, permitindo incluir este grupo populacional no acesso aos serviços de saúde, ao mesmo tempo, que valoriza os saberes tradicionais da população quilombola.

Gráfico 2: Número de publicações sobre a população quilombola entre 2009-2016. Fonte: Banco de Teses da CAPES, SciELO, BVS e PUBMED (2009-2016)

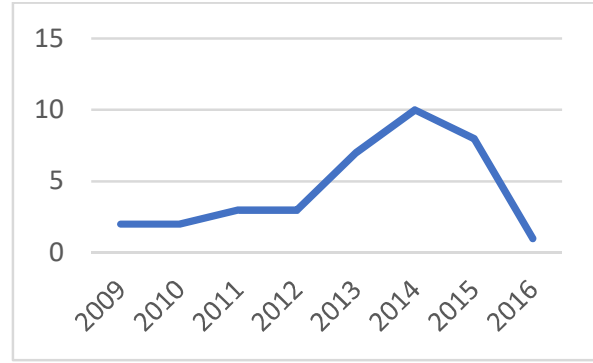

Destaca-se também a abordagem para patologias predominantes na população negra como a Hipertensão, o Diabetes e a anemia falciforme. 


\section{CONSIDERAÇÕES FINAIS (ou Conclusão)}

A pesquisa finalizada após a análise dos Projetos Políticos Pedagógicos das Universidades aponta que os cursos da área de saúde ainda negligenciam a PNSIPN e, assim, que é urgente a necessidade de capacitar professores formadores, profissionais em serviço, gestores e estudantes sobre a necessidade de abordar conteúdo específicos sobre saúde da população negra e também valorizar a formação do profissional voltada para a integração entre os saberes científicos e populares, valorizando a cultura e a crença deste grupo populacional, indicando também a necessidade de criação de instrumentos para a informação, formação e avaliação da implementação das políticas de saúde no Brasil.

No estudo que buscou caracterizar a produção científica indexada nas bases de dados SciELO, BVS e PUBMED e no banco de dissertações e Teses da CAPES relacionada à temática da Saúde da População Negra, os resultados encontrados permitem perceber a importância da análise do estado da arte de uma temática para a contribuição na tomada de decisão sobre as necessidades de intensificar a pesquisa no Brasil. O levantamento bibliográfico, a partir das bases consultadas, aponta crescimento da abordagem temática sobre saúde da população negra em 2009, 2013 e 2014. Esse crescimento pode ser devido ao aumento do conhecimento tanto dos profissionais da saúde quanto da população em geral sobre a existência da PNSIPN e das campanhas contra o racismo institucional promovidas pelo Ministério da Saúde desde 2010. Porém, desde 2014 as publicações estão diminuindo, devendo-se intensificar as discussões sobre a temática.

\section{REFERÊNCIAS}

Brasil. Ministério da Saúde. Secretaria de Gestão Estratégica e Participativa. Departamento de Apoio à Gestão Participativa. Política Nacional de Saúde Integral da População Negra : uma política para o SUS / Ministério da Saúde, Secretaria de Gestão Estratégica e Participativa, Departamento de Apoio à Gestão Participativa. - 2. ed. - Brasília: Editora do Ministério da Saúde, 2013.

Brasil. Ministério da Saúde. Secretaria de Gestão Estratégica e Participativa. Departamento de Apoio à Gestão Participativa. Política Nacional de Saúde Integral da População Negra : uma política para o SUS / Ministério da Saúde, Secretaria de Gestão Estratégica e Participativa, Departamento de Apoio à Gestão Participativa. - Brasília: Editora do Ministério da Saúde, 2010.

GIL, Antonio Carlos. Como elaborar projetos de pesquisa. 4. ed. São Paulo: Atlas, 2008

MONTEIRO, Simone; CECCHETTO, Fátima. Cor, gênero e classe: dinâmicas da discriminação entre jovens de grupos populares cariocas. Cad. Pagu, Campinas, n. 32, p. 301329, June $2010 \quad$ Available from $<$ http://www.scielo.br/scielo.php?script=sci_arttext\&pid=S0104$83332009000100010 \& \operatorname{lng}=\mathrm{en} \& \mathrm{nrm}=\mathrm{iso}>$. access on 29 Nov. 2016. 